\section{Tennis enhances well-being in university students}

\author{
Ahmet Bulent Yazici,1 Mine Gul,2 \\ Esra Yazici,1 Gazanfer Kemal Gul2 \\ 1Department of Psychiatry, Medical \\ Faculty, Training and Research Hospital, \\ Sakarya University, Sakarya; ${ }^{2}$ School of \\ Physical Education and Sports, Kocaeli \\ University, Kocaeli, Turkey
}

\section{Abstract}

Sports and physical activity are widely recommended, both as guidelines and in clinical practice, because of their broad range of positive effects on health, depression, anxiety, and psychological well-being. While several studies have examined the anti-depressive and anxiolytic effects of physical activity in clinical populations, and fewer studies have focused on the nonclinical populations, the relationship between tennis and well-being has not been clearly investigated. This study was carried out with 76 student volunteers from Kocaeli University (Turkey) who had chosen tennis lessons as their University. The tennis exercise program consisted of 90 -minute basic tennis skills lessons for 13 weeks. At the beginning and at the end of the study, the students were given the Symptom Checklist-90-Revised (SCL-90-R), the Beck Anxiety Inventory (BAI), and the Beck Depression Inventory (BDI) scales, and were evaluated by the DeWittDugan Tennis Service Test, the DeWitt-Dugan Speed Test, and the Dyer Backboard Tennis Test. Upon evaluating the students' pre- and post-test scores, we concluded that their BDI and BAI scores had significantly decreased, with the most significant decreases seen in several sub-scores of the SCL-90-R; their tennis skills, meanwhile, increased significantly. This study shows that partaking in tennis exercise once a week decreases depression and anxiety symptoms and enhances well-being in healthy young people.

\section{Introduction}

Well-being is a multifaceted concept that includes psychological, social, and physical components. Operationally defining psychological well-being is difficult because of this multifaceted nature. As Brown states, psychological well-being may be related to self-esteem, cognitive functioning, personality, and mood, including positive affects such as happiness, vigor, and morale, and negative affects such as

\section{anxiety and depression. 1}

No study can realistically include the entire spectrum of this concept. ${ }^{2}$ One aspect of psychological well-being may be defined as the absence of negative psychological symptoms such as anxiety, depression, anger, and hostility; therefore, any approaches that contribute to decreased levels of anxiety, depression, and other psychological symptoms are thought to extend psychological well-being. ${ }^{3}$

The practice of a sport, because of its broad range of positive effects on health and psychological well-being, is often prescribed for overall physical fitness, and is also widely used as part of physicians' clinical practice in healing patients. ${ }^{4,5}$ Researchers generally believe that physical activity has a positive effect on mood and anxiety. Intervention studies have described the anxiolytic and anti-depressive effects of exercise in healthy subjects and patients. ${ }^{6}$ Many meta-analytical studies and reviews have demonstrated the benefits of exercise on anxiety in both clinical and nonclinical populations. World Health Organization (WHO) suggests regular exercise for both clinical and nonclinical populations to enhance well-being and health in all of its physical, social, and psychological aspects. ${ }^{7}$ The healing effects of exercise are widely accepted, and affiliated with its ability to regulate serotonin, dopamine, and noradrenaline levels in the brain, increasing the brainderived neurotrophic factor (BDNF) levels, and controlling effect on oxidative stress. It is recommended as a complimentary treatment choice in depression and anxiety disorders. ${ }^{8-10}$

Recently, in terms of health benefits, questions have been raised about the amount and type of exercise, the frequency, the length of the exercise session, and which kinds of sports. Researchers have examined aerobic sports versus anaerobic sports, low-intensity versus high-intensity sports, and low-frequency versus high-frequency sports, as well as surfing, stretching, walking, dancing, etc.

Tennis is a sport with numerous health benefits for individuals of all ages. It is also a tremendously effective fitness activity. Regular participants experience a wide variety of health-related physical and mental benefits, ranging from improved cardiovascular, metabolic, and bone health to improved agility and coordination, and even stress and anxiety management. Tennis both challenges and builds an individual's aerobic and anaerobic conditioning, and also requires tremendous muscular strength and endurance. 11 According to Finn, 12 compared with other athletes as well as non-athletes, tennis players scored higher in vigor, optimism, and self-esteem, while scoring lower in depression, anger, confusion, anxiety, and tension. Tennis outperforms golf and most other sports in developing positive personality characteristics. ${ }^{13}$
Correspondence: Ahmet Bulent Yazici, Department of Psychiatry, Training and Research Hospital, Sakarya University, Korucuk street, 54050 Adapazari, Turkey.

Tel.:+90.5325994988 - Fax:+90.2642552105.

E-mail: a.bulentyaz@gmail.com

Key words: Tennis; depression; anxiety; wellbeing; sport.

Contributions: the authors contributed equally. Conflict of interest: the authors declare no potential conflict of interest.

Received for publication: 18 March 2016.

Revision received: 13 April 2016.

Accepted for publication: 21 April 2016.

This work is licensed under a Creative Commons Attribution-NonCommercial 4.0 International License (CC BY-NC 4.0).

(C) Copyright A.B. Yazici et al., 2016

Licensee PAGEPress, Italy

Mental Illness 2016; 8:6510

doi:10.4081/mi.2016.6510

While many studies have proclaimed the anti-depressive and anxiolytic effects of different kinds and doses of physical activity for clinical populations, ${ }^{14-16}$ the benefits of physical activity, and specifically tennis, for reducing depression and anxiety in nonclinical populations have not been promoted to the same extent. ${ }^{17}$ WHO states the importance of wellbeing in non-clinical populations, especially in young people, and emphasizes that interventions with youth can positively influence mental health and reduce risk factors as well as emotional and behavioral problems. ${ }^{18}$ In this study, we hypothesized that tennis may have an healing effect on psychological symptoms in young students. We investigated the question of whether tennis has beneficial effects on depression, anxiety, and general psychological improvement in a nonclinical population of young people.

\section{Materials and Methods}

\section{Participants}

This study was conducted with 80 students from Kocaeli University who chose tennis lessons among their elective activities. All of the students were volunteers, but 4 of the students (2 males and 2 females) did not completely participate in all of the training sessions. So they were excluded from the study. 76 students [ 44 males and 32 females, with an average age of $20.93 \pm 0.75$ years (range: $20-22$ years)] completed the whole program and took all of the tests. None of the students were from the 
Faculty of Physical Education and Sports, none had any professional background in sports, and none had any previous training in sports. None of the students were enrolled in any additional sporting sessions during the study.

\section{Procedure}

The students were given a Symptom Checklist-90-Revised (SCL-90-R), the Beck Anxiety Inventory (BAI), and the Beck Depression Inventory (BDI) at the beginning of the study. Based on the information we obtained from the interviews, none of the students had psychiatric diagnoses, and none were receiving active psychiatric treatment.

Students completed the BAI, BDI, and SCL90-R prior to participating in any physical activities. Basic tennis training then started. This training consisted of 90 -minute lessons held once per week for 13 weeks at the Kocaeli University Physical Training and Sports High School Tennis practice room. The lessons began with stretching for 5 minutes and jogging for 10 minutes, followed by 75 minutes of sportive activity based on tennis skills. Forehand, backhand, and basic service skills were practiced at every lesson during the basic tennis training. The participants' tennis skill tests were evaluated before and after the study.

Official approval was obtained for the study from the Kocaeli University Ethical Committee. All volunteer students who did not have a known psychiatric-somatic illness were accepted for the study. All of the students were informed about the process, measurements, and rules of the study, and they all provided their oral and written consent to participate.

\section{Instruments}

The instruments used for the study were selected by analyzing previous studies about sport, well-being, and psychiatry/psychology; scales that are widely used in the assessment of psychiatric/psychological symptom severity in clinical populations, and in epidemiological studies in nonclinical populations, were preferred.

\section{Psychometric tests}

\section{Symptom Checklist-90-R}

The SCL-90-R was developed by Derogatis, and colleagues in 1973. The SCL-90-R was normed using 4 groups of psychiatric, non-psychiatric, and adolescent individuals, for a total of 3092 participants. Reliability assessment of the subscales has yielded internal consistency estimates ranging from 0.77 to 0.90 and testretest estimates ranging from 0.78 to 0.90 .19 Later, it was adapted into Turkish by Kılıc; 20 in addition, Dag performed the validity and reliability studies of the SCL-90-R test with the Cronbach's alpha value $=0.97$, and the testretest reliability of the subgroups was 0.65 , 0.87 , and 0.90 .21 The SCL-90-R consists of 10 factors of somatization (12 items), obsessivecompulsive symptoms (10 items), interpersonal sensitivity (9 items), depression (13 items), anxiety (10 items), anger/hostility (6 items), phobic anxiety (7 items), paranoid thoughts (6 items), psychoticism (10 items), and additional scales (insomnia, anorexia, guilt) (7 items). The total score from a subgroup was then divided by the number of items included in that subgroup to obtain the subgroup score.

\section{Beck Depression Inventory}

Participants' emotional levels were assessed using the Turkish version of the BDI, which is a 21-question multiple-choice self-reported inventory, and one of the most widely used instruments for measuring the severity of depression. Its development marked a shift among health care professionals, who had until then viewed depression from a psychodynamic perspective, rather than viewing it as being rooted in the patient's own thoughts. Each answer to the 21 questions is scored on a scale value of 0 to 3 . Higher total scores indicate more severe depressive symptoms. ${ }^{22}$ The internal consistency has been confirmed by numerous studies in psychiatric and non-psychiatric samples. Most of the researchers report alpha-coefficients that are on average higher than 0.75 . According to Richter, the average coefficient for psychiatric samples amounts to 0.88 , and the corresponding score for the non-psychiatric samples is $0.82 .{ }^{23} \mathrm{Hisli}$ and later Kapci conducted a study on the Turkish version's reliability and validity, with a Cronbach's alpha value $=0.80 .24,25$

\section{Beck Anxiety Inventory}

The BAI is a 21-item inventory designed to assess levels of anxiety. ${ }^{26}$ It measures physical, emotional, and cognitive aspects of anxiety and fear of losing control. The score for each item ranges from 0 to 3 . The maximum score on the scale is 63 , with $0-7=$ minimal level of anxiety; $8-15=$ mild anxiety; $16-25=$ moderate anxiety; and 26-63=severe anxiety. Its original version by Beck had internal consistency with a Cronbach's alpha value of 0.92 , and a retest reliability coefficient of $r=0.75$. Ulusoy and colleagues conducted a validity and reliability study of the Turkish version of the BAI, and found that it was applicable to the Turkish population. 27

\section{Tests used to measure basic tennis skills}

\section{DeWitt-Dugan Tennis Service Test (Service T)}

In this test, the subject had 10 service throws in accordance with the rules. If the throw was successful, it was given one point. If the throw was made in accordance with the rules, but not recorded as a hit, it was granted half a point. The total score was determined from the total points scored at the end of 10 throws. ${ }^{28}$

\section{DeWitt-Dugan Speed Test (Speed T)}

In this test, the subject hit the ball against a wall for 1 minute, using any hitting technique. There was a minimum 3 meters of distance between the subject and the wall; the score was determined by the number of balls that hit the wall during this time. 28

\section{Dyer Backboard Test}

As devised by Dyer in 1935, this test consists merely of bouncing a tennis ball above a specified line on a wall for a 30 -second period. This rally was initiated $6.09 \mathrm{~m}$ from the wall, and only those shots that hit the wall above a 91.5cm-high line (representing the net) were counted. Once the rally was started, students could move as close to the wall as they wished. In 1938, Dyer revised the test by adding a restraining line 1.5 meters from the wall. ${ }^{29}$

\section{Statistical analysis}

Statistical analysis was conducted using the statistical packet program SPSS v.17.00 for Windows XP. Groups were controlled with Levine's test for homogeneity, and the comparison of continuous variables was performed with independent samples using a Student's $t$ test. Categorical variables of the students (such as gender) were compared with the chisquare test between groups, and numerical variables (such as test scores) were compared with the Student's $t$-test. In addition, repeated measures of ANOVA analysis were used to minimize the Type I error. The significance level was set at $\mathrm{P}<0.05$.

\section{Results}

This study was conducted with university students; no significant differences were observed between the genders in terms of tennis skills, BAI, BDI, or SCL-90-R scores ( $\mathrm{P}>0.005)$. In order to test our assumption that anxiety and depression scores would decrease after tennis training, pre- and post-test scores were compared as independent samples. Upon evaluating the pre- and post-test scores with a Student's $t$-test, we found that tennis skills significantly increased, and BAI and BDI scores significantly decreased $(\mathrm{P}<0.005$; Table 1$)$.

We also assumed that scores of general psychopathology, which we measured with SCL90, should become lower after tennis training. Evaluations of the general symptoms of the students were conducted with the Student's $t$ test; the SCL-90-R scores were calculated separately for subgroups and total scores. We found significant differences for all of the 
scores before and after tennis training; the scores after tennis training were significantly lower (Figure 1).

During repeated measures, the ANOVA test found that decreases in the BAI scores were significant in double measurements (pretest/post-test $) \quad(\mathrm{F}=4.386, \quad \mathrm{P}=0.040) ; \quad$ the decrease in BDI scores was also significant ( $\mathrm{F}=9.070, \mathrm{P}=0.004)$.

Repeated measure analysis was also conducted for subscales of SCL-90; decreased somatization, obsessive-compulsiveness, hostility, and psychoticism scores were not significant $(\mathrm{P}>0.05)$. Changes in the scores of interpersonal sensitivity $(\mathrm{F}=7.529, \mathrm{P}=0.008)$, depression $(\mathrm{F}=5.437, \mathrm{P}=0.022)$, anxiety $(\mathrm{F}=5.750$, $\mathrm{P}=0.019)$, phobia $(\mathrm{F}=9.060, \mathrm{P}=0.004)$, paranoid thoughts $(\mathrm{F}=4.176, \mathrm{P}=0.045)$, and additional factor scale (insomnia, anorexia, guilt; $\mathrm{F}=15.579, \mathrm{P}=0.000)$ scores were significant. Total SCL-90-R scores were also evaluated, and the change was significant $(\mathrm{F}=9.644$, $\mathrm{P}=0.003)$. The significant scores are flagged in Figure 1.

The reliability of the measurements for the current study was calculated with the current sample, with a Cronbach's alpha $=0.914$ for BAI, 0.851 for BDI, and 0.967 for SCL-90-R, respectively.

\section{Discussion}

This study showed that BAI, BDI, and total SCL-90-R scores (and all sub-scores) among university students decreased with basic tennis training that took place for 90 minutes per week for 13 weeks.

In previous studies, the dose and types of exercise, its frequency, duration, length of the exercise session, and kinds of sports were investigated. Aerobic sports versus anaerobic sports, low-intensity versus high-intensity sports, and low-frequency versus high-frequency sports, as well as surfing, stretching, walking, dancing, etc. have been examined. This study presents tennis, at 90 minutes per week for 13 weeks, as a sport with healing properties.

\section{Anxiety-tennis relationship}

We found that the anxiety scores that were measured before sporting activity significantly decreased after a 13-week sport training and exercise program. An investigation was performed into the ways in which exercise programs need to be designed in order to exert the largest anxiolytic effect. The duration of the programs, weekly frequency of exercise ses-

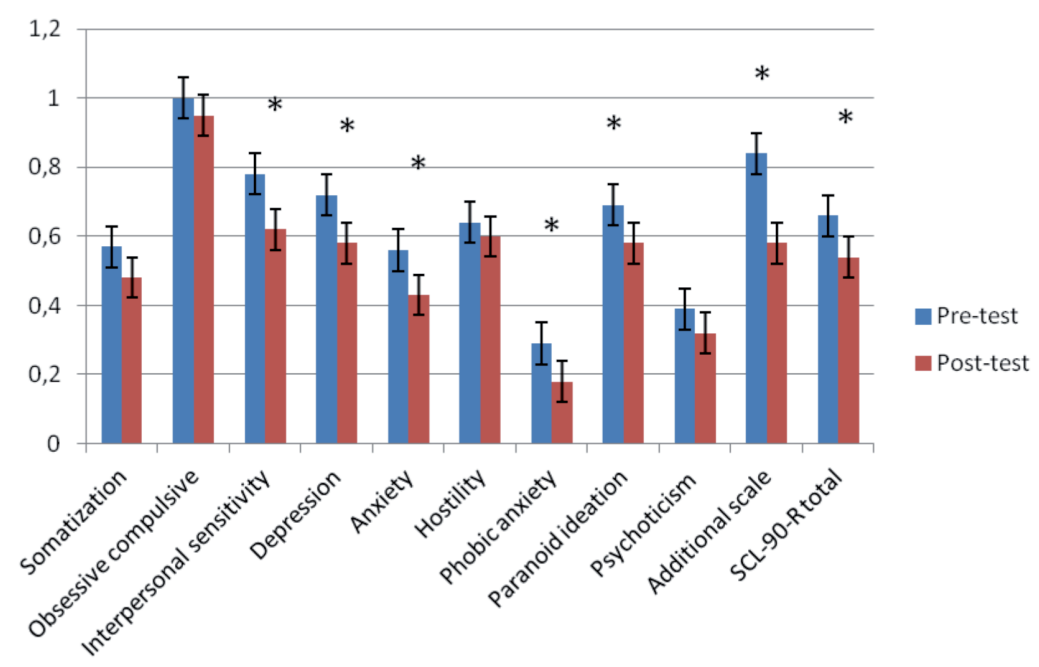

Figure 1. Students' Symptom Checklist-90-R scores before and after tennis training $\left({ }^{*} \mathbf{P}<0.05\right.$ with repeated measures of ANOVA analysis).

Table 1. Students' anxiety, depression and tennis skill scores before and after tennis training.

\begin{tabular}{lcccc} 
& Pre-test & Post-test & $\mathrm{t}$ & $\mathrm{P}$ \\
BAI total scores & $9.01 \pm 9.29$ & $7.28 \pm 7.49$ & 2.094 & $<0.00$ \\
BDI total scores & $8.56 \pm 7.05$ & $6.80 \pm 6.37$ & 3.012 & $<0.00$ \\
\hline Service test & $7.67 \pm 1.20$ & $8.11 \pm 1.11$ & -2.983 & $<0.00$ \\
Speed test & $30.97 \pm 7.37$ & $37.78 \pm 7.02$ & -10.773 & $<0.00$ \\
\hline Dyer Backboard test & $30.0 \pm 10.72$ & $35.44 \pm 13.35$ & -8.140 & $<0.00$ \\
\hline
\end{tabular}

BAI, Beck Anxiety Inventory; BDI, Beck Depression Inventory.

sions, and session lengths were discussed. There have been varying recommendations for the duration of programs. Some authors have suggested that the duration of the intervention is not a variable for the anxiolytic effect of exercise, and others have declared variable lengths as the optimum. Programs of 3-12 weeks were reported to have the largest effect sizes. 7,30 Regarding the frequency of exercise, generally 3 to 4 sessions per week has been shown to be most effective, but some studies recommended 3 to 5 times per week. The length of time spent per session is also shown to be important, but there is uncertainty in this area as well.17,7 The average length in studies that found significant effects was 106 min per week (60-125 min per week). ${ }^{31}$ Generally, recommended length ranges vary between 20 to 90 minutes. ${ }^{7}$ The average duration of intervention in studies that found significant effects was 12.8 weeks (1-20 weeks). ${ }^{32}$ However, in general review of the extant studies, no standard recommendations for practice can be given. ${ }^{7,32}$ The present study seems to be similar in terms of duration (weeks) and length (minutes) of the exercise in the literature, but the frequency is different. This study provides an alternative choice of exercise to previous studies.

\section{Depression-tennis relationship}

In our study, the BDI scores (which were determined before the tennis program) significantly decreased after the program. Many studies of exercise programs have shown that sport and exercise can significantly decrease depressive scores, and there are many reviews and meta-analyses that show the healing effect of exercise on depressive symptoms, both in healthy volunteers and in depressive people; however, the kind, duration, and frequency of the exercise is still in question. ${ }^{7}$ To our knowledge, however, studies on the effect of tennis on depression in healthy individuals are limited.

Durations have been studied in a wide range, from under 12 to over 26 weeks, and a medium program of 10-16 weeks is recommended for depressive symptoms.30,33 When the frequency of exercise sessions have been investigated, some authors recommended a medium frequency of exercise 3 or 4 times a week, and the American College of Sports Medicine recommends 5 times per week. ${ }^{7}$ Length of the sessions generally varies from 20 to 90 minutes in studies. In addition, aerobic and anaerobic exercises have been compared in studies, and larger effect sizes in lowering depressive symptoms were observed for aerobic compared to other types of exercise. ${ }^{33}$ For instance, a study by Roth and Holmes, working with 1051 students, had one group of students engage in aerobic exercise while another group engaged in relaxation training. The 
researchers worked with both groups for 30 minutes 3 days per week for 11 weeks; they determined that BDI scores decreased in the aerobic exercise group, and that the aerobic exercise was more effective in reducing the depressive symptoms when compared to the other group. ${ }^{34}$ Another study had individuals performing programmed aerobic walking exercises, with pre- and post-testing compared to a control group. According to the BDI scores, having performed walking aerobic exercises, there were significant differences between the experimental and control groups, and the exercise group showed less depression after the exercise. 35

It is generally believed that tennis both challenges and builds an individual's aerobic and anaerobic conditioning, and also requires tremendous muscle strength and endurance. ${ }^{11}$

Our results also show that, like other physical activities, tennis is successful in reducing depression scores. Previous studies show that exercise has the effect of regulating serotonin, dopamine, and noradrenaline function in the human brain, changing levels of endorphin, anandamide, and cortisol, restoring limbic structures that have been negatively implicated in depression, and increasing BDNF level.., 36 Tennis is a kind of exercise, and may have a similar effect mechanism. This may mediate its lowering effect on anxiety and depression scores. The mechanisms of effect of tennis on mood require further study.

\section{General health subtitles}

SCL-90-R scores show the severity of general psychological symptoms of a subject; in our study, we found significant decreases in both total scores and sub-scores following a 13week program of exercise and tennis skill training. In repeated measures testing, decreases in the scores of interpersonal sensitivity, depression, anxiety, phobia, paranoid thoughts, and additional factors scales (insomnia, anorexia, guilt) were significant, as were total SCL-90 scores. This suggests that sports leads to an integrated recovery in mental health in the symptom group, as is the case with depression.

One study assessed differences in psychological well-being between wheelchair-bound basketball participants and non-participants with self-report questionnaires (SCL-90-R), and showed significant overall differences between the two groups. The SCL-90-R scores were significantly lower for the basketball group in the following six symptomatic dimensions: depression, phobic anxiety, sleep disorders $(\mathrm{P}<0.01$ for all), and somatization, interpersonal sensitivity, and psychoticism $(\mathrm{P}<0.05$ for all). No significant differences were found in the anxiety, obsessive-compulsive disorder, hostility, and paranoid dimensions. ${ }^{37}$ Similarly, other studies have found that exercise reduces some or all dimensions of the SCL-90-R scores among blind Torball players, ${ }^{37}$ postmenopausal women, and cancer patients undergoing chemotherapy. $.88,39$

This study presents tennis, with its healing effect, in an integrative manner, as judged by anxiety depression and sub-scores on the SCL90 for interpersonal sensitivity, depression, anxiety, phobia, paranoid thoughts, and additional factors scales (insomnia, anorexia, guilt). The study is conducted with young healthy university students. Young people are at risk of anxiety and depression, and need to cope with stressful life events as well as the stress of lessons and exams. ${ }^{18}$ According to our results, we can say that playing tennis may contribute to enhancing the well-being of university students. Integrative approaches that include sport lessons for all the programs, even if the curriculum of the program is not related with sports, may be recommended to schools. of course, this study highlights tennis as a recommendation with its results. In addition, we think that tennis will find a place in recommendations of clinicians for other non-clinical and clinical populations for healing psychological symptoms and enhancing well-being. Future studies may provide different duration and frequency options in different populations.

We want to highlight once a week exercise specifically tennis as a sub result of this study, which should be discussed and investigated in further studies.

The limitations of the study include the small sample size, and the self-reported rating scales rather than face-to-face psychiatric examinations. In addition, the study group was based on students who elected to take tennis, so there may be a self-selection bias. The strength of the study is its prospective design, which presents psychological measurements for a nonclinical population, as well as the fact that the subjects did not have previous training in sports, which may provide a clearer look at the effect of tennis. This study suggests that participating in a sport (and specifically tennis) once weekly for 90 minutes for 13 weeks has a beneficial effect on psychological wellbeing among young university students.

\section{Conclusions}

This study brings about discussion of the topics on the relationship between sport and mental health. First, this study confirms a wellknown reality that sports increase well-being in individuals, but it differs from most previous studies in that it demonstrates the beneficial effects of tennis in a nonclinical group of young people. According to our results, its effects are beneficial in reducing depression, anxiety, and general mental health symptoms among young people. As a second conclusion, this study presents an alternative answer to the question of what length, duration, and frequency of participating in sport is beneficial for improving psychological symptoms; it suggests that 90 minutes of tennis training once per week for 13 weeks is effective in decreasing various psychological symptoms.

\section{References}

1. Brown DR. Physical activity, ageing, and psychological well-being: an overview of the research. Can J Sport Sci 1992;17:18593.

2. Hassmén P, Koivula N, Uutela A. Physical exercise and psychological well-being: a population study in Finland. Prev Med 2000;30:17-25.

3. McAuley E, Rudolph DL. Physical activity, aging, and psychological well-being. $\mathrm{J}$ Aging Phys Act 1995;3:67-96.

4. Merglen A, Flatz A, Bélanger RE, et al. Weekly sport practice and adolescent wellbeing. Arch Dis Child 2014;99:208-10.

5. Folkins CH, Sime WE. Physical fitness training and mental health. Am Psychol 1981;36:373-89.

6. Tordeurs D, Janne P, Appart A, et al. [Effectiveness of physical exercise in psychiatry: a therapeutic approach?]. Encephale 2011;37:345-52. [Article in French]

7. Wegner M, Helmich I, Machado S, et al. Effects of exercise on anxiety and depression disorders: review of meta- analyses and neurobiological mechanisms. CNS Neurol Disord Drug Targets 2014;13:100214.

8. Marais L, Stein DJ, Daniels WM. Exercise increases BDNF levels in the striatum and decreases depressive-like behavior in chronically stressed rats. Metab Brain Dis 2009;24:587-97.

9. Medina JL, Jacquart J, Smits JA. Optimizing the exercise prescription for depression: the search for biomarkers of response. Curr Opin Psychol 2015;4:43-7.

10. He SB, Tang WG, Tang WJ, et al. Exercise intervention may prevent depression. Int $\mathrm{J}$ Sports Med 2012;33:525-30.

11. Groppel J, DiNubile N. Tennis: for the health of it! Phys Sportsmed 2009;37:4050 .

12. Finn JA. Characteristics for predicting success among highly skilled youth tennis players. USTA Research GrantInformation. Dr. J.A. Finn, Southern Connecticut State University, New Haven, Conn. 06515.; 1990. Available from: http://uspta.com/html/HealthBooklet.pdf

13. Gavin J. Pairing exercise with activity: 
new tools for inspiring active lifestyles. Phys Sportsmed 2004;32:17-24.

14. Davidson JR, Feltner DE, Dugar A. Management of generalized anxiety disorder in primary care: identifying the challenges and unmet needs. Prim Care Companion J Clin Psychiatry 2010;12.

15. Morgan AJ, Parker A, Alvarez M, Jorm A. Exercise and mental health: an exercise and sports science Australia commissioned review. J Exerc Physiol Online 2013;16:64-73.

16. Ravindran AV, da Silva TL. Complementary and alternative therapies as add-on to pharmacotherapy for mood and anxiety disorders: a systematic review. J Affect Disord 2013;150:707-19.

17. Rebar AL, Stanton R, Geard D, et al. A meta-meta-Analysis of the effect of physical activity on depression and anxiety in non-clinical adult populations. Health Psychol Rev 2015:1-78.

18. Sancassiani F, Pintus E, Holte A, et al. Enhancing the emotional and social skills of the youth to promote their wellbeing and positive development: a systematic review of universal school-based randomized controlled trials. Clin Pract Epidemiol Ment Health 2015;11:21-40.

19. Derogatis LR, Cleary PA. Confirmation of the dimensional structure of the scl-90: A study in construct validation. J Clin Psychol 1977;33:981-9.

20. Kilic M. Belirti Tarama Listesi (SCL-90R)'nin Geçerlilik ve Güvenirli i. Psikolojik Danısma Ve Rehberlik Dergisi 1991;1:4552.

21. Dag I. Belirti Tarama Listesi (Scl-90R)'nin Üniversite Ö rencileri için güvenirli $i$ ve geçerli i/Reliability and validity of the Symptom Check List (SCL-90-R) for university students. Turkish J Psychiatry. 1991;2:5-12.

22. Beck AT, Steer RA, Brown GK. Manual for the Beck Depression Inventory-II. San Antonio, TX: Psychological Corporation; 1996.

23. Richter P, Werner J, Heerlein A, et al. On the validity of the Beck Depression Inventory. A review. Psychopathology 1998;31:160-8.

24. Hisli N. A study on the validity of Beck Depression Inventory. Turkish J Psychol 1988;6:118-23.

25. Kapci EG, Uslu R, Turkcapar H, Karaoglan A. Beck Depression Inventory II: evaluation of the psychometric properties and cut off points in a Turkish adult population. Depress Anxiety 2008;25:E104-E10.

26. Beck AT, Epstein N, Brown G, Steer RA. An inventory for measuring clinical anxiety: psychometric properties. J Consult Clin Psychol 1988;56:893-7.

27. Ulusoy M, ahin NH, Erkmen H. Turkish version of the Beck Anxiety Inventory: psychometric properties. J Cogn Psychother 1998;12:163-72.

28. Kamar A. Sporda Yetenek Beceri ve Performans Testleri. Nobel Yayın Da itım; 2008.

29. Hewitt JE. Revision of the Dyer Backboard Tennis test. Res Q Exercise Sport 1965;36:153-7.

30. Herring MP, O'Connor PJ, Dishman RK. The effect of exercise training on anxiety symptoms among patients: a systematic review. Arch Intern Med 2010;170:321-31.

31. Dyer JB 3rd, Crouch JG. Effects of running and other activities on moods. Percept Mot Skills 1988;67:43-50.

32. Netz Y, Wu MJ, Becker BJ, Tenenbaum G. Physical activity and psychological well- being in advanced age: a meta-analysis of intervention studies. Psychol Aging 2005;20:272-84.

33. Rethorst CD, Wipfli BM, Landers DM. The antidepressive effects of exercise: a metaanalysis of randomized trials. Sports Med 2009;39:491-511.

34. Roth DL, Holmes DS. Influence of aerobic exercise training and relaxation training on physical and psychologic health following stressful life events. Psychosom Med 1987;49:355-65.

35. Aylaz R, Güllü S, Güne G. Aerobik Yürüme Egzersizin Depresif Belirtilere Etkisil"influence of Aerobic Walking Exercises on Depression Symptoms". Dokuz Eylül Üniversitesi Hem irelik Yüksekokulu Elektronik Dergisi. 2011;4:172-7.

36. Heijnen S, Hommel B, Kibele A, Colzato LS. Neuromodulation of aerobic exercise-a review. Front Psychol 2015;6:1890.

37. Di Cagno A, Iuliano E, Aquino G, et al. Psychological well-being and social participation assessment in visually impaired subjects playing Torball: a controlled study. Res Dev Disabil 2013;34:1204-9.

38. Agıl A. Postmenopozal kadınlarda kısa dönem farklı egzersiz yakla ımlarının menopozal semptomlar, psikolojik sa lık ve ya am kalitesi üzerine etkileri. Ankara: Baskent University; 2010.

39. Dimeo FC, Stieglitz RD, Novelli-Fischer U, et al. Effects of physical activity on the fatigue and psychologic status of cancer patients during chemotherapy. Cancer 1999;85:2273-7. 